\title{
Ujian nasional sebagai wacana pendidikan
}

\author{
Rosmawati $\mathrm{T}^{1^{*}}$, Yuyun Febriani² \\ 1,2Prodi Bimbingan dan Konseling, Universitas Muhammadiyah Buton, Indonesia \\ "Korespondensi: rosmawatitaherong123@gmail.com
}

\begin{tabular}{|c|c|}
\hline Info Artikel & \multirow{7}{*}{$\begin{array}{l}\text { Abstrak } \\
\text { Penelitian ini di tujukan untuk mengkaji sebab yang mendasari terjadinya } \\
\text { ragam wacana dalam membentuk persepsi social akan pentingnya } \\
\text { pelaksanaan ujian nasional yang di terapkan sebagai standar pendidikan } \\
\text { nasional. Kajian di lakukan melalui pendekatan sosiologi Pendidikan } \\
\text { dengan model deskriptif kualitatif menggunakan pusposivesampel melalui } \\
\text { responden terpilih. Kajian ini menemukan bahwa, Komponen ujian } \\
\text { nasional menjadi simpang siur dalam pelaksanaannya. Hal ini berlaku oleh } \\
\text { karena beberapa faktor yang mendasari munculnya kebijakan mutu ujian } \\
\text { nasional yakni, pertama; Kopetensi pendidikan yang memuat beragam } \\
\text { materi, nilai, dan sebagainya seolah dikesampingkan dalam pelaksanan } \\
\text { UN karena dalam prakteknya memuat beberapa materi yang } \\
\text { dikelompokkan sebagai bahan yang di ujikan, kedua; adanya standar } \\
\text { angka kelulusan yang harus dikejar agar dinyatakan lulus tanpa } \\
\text { menghiraukan etika dan moral yang digagas dalam hakikat pendidikan } \\
\text { nasional. } \\
\text { Abstract } \\
\text { This research is aimed at examining the reasons underlying the various } \\
\text { discourses in shaping social perceptions of the importance of } \\
\text { implementing national exams which are applied as national education } \\
\text { standards. The study was carried out through a sociological approach to } \\
\text { education with a qualitative descriptive model using a sample center } \\
\text { through selected respondents. This study found that the components of the } \\
\text { national exam were confusing in its implementation. This is true because } \\
\text { of several factors that underlie the emergence of the national exam quality } \\
\text { policy, namely, first; Competence education which contains a variety of } \\
\text { materials, values, and so on seems to be sidelined in the implementation } \\
\text { of the National Examination because in practice it contains several } \\
\text { materials which are grouped as material being tested, second; There is a } \\
\text { graduation rate standard that must be pursued in order to pass without } \\
\text { considering the ethics and morals that are initiated in the essence of } \\
\text { national education. }\end{array}$} \\
\hline Diterima 2 & \\
\hline & \\
\hline $\mathrm{Ke}$ & \\
\hline & \\
\hline & \\
\hline & \\
\hline
\end{tabular}

\section{Pendahuluan}

Pendidikan diselenggarakan untuk manusia Indonesia, sehingga memiliki kemampuan mengembangkan diri, meningkatkan mutu kehidupan, meningkatkan martabat dalam rangka mencapai tujuan nasional. Upaya mencapai tujuan pendidikan nasional adalah untuk menciptakan masyarakat madani yaitu 
masyarakat yang berperadaban menjunjung nilai-nilai kemanusiaan yang sadar akan hak dan kewajibannya, demokratis, bertanggung jawab, berdisiplin, menguasai sumber informasi dalam bidang iptek, seni, budaya dan agama.

Secara sederhana, kajian sosiologi pendidikan bertalian dengan analisis ilmiah tentang proses interaksi sosial yang terkait dengan aktifitas pendidikan, baik dikeluarga, kehidupan sosio-kultural masyarakat maupun pada taraf objektif tentang relasi sosial yang menyusun kontruksi total realitas pendidikan di suatu negara (Nasution, 2009). Sampai pada pemahaman tersebut segala bentuk wawasan dan pengetahuan sosiologis guna membedah tubuh pendidikan nasional menjadi perlu dibahas agar proses-proses pembalajaran berlangsung tetap relevan dengan kebutuhan bangsa (Irianto, 2011).

Di sini, kriteria sekolah sebagai wadah pendidikan formal memberikan gagasan baru dalam pelaksanaan sistem yang memuat kebijakan akan ujian nasional yang diadakan setiap akhir semester pada tingkat akhir atau pada akhir tahun pembelajaran (Muntholi'ah, 2013). Selanjutnya dimensi ujian nasional dimasukkan sebagai wadah dari evaluasi proses pembelajaran yang dikelompokkan kedalam beberapa mata pelajaran yang kita kenal dengan sebutan kelompok IPA, IPS, dan Bahasa (Nurul Hidayah, 2013). Hal ini memberikan pemahaman akan perbedaan ilmu pada kapasitas yang lebih sempit dan mana yang lebih unggul.

Jika perhatian tertuju pada pemahaman akan bentuk rumpun ilmu tersebut maka secara langsung perhatian dan pembelajaran disekolah hanya akan diminati kedalam pokok-pokok pembahasan yang memuat tentang kelompok IPA, IPS dan Bahasa (Nursyam, 2017) Kendatipun demikian, gagasan dalam ujian nasional perlu dikaji kembali dalam pelaksanaanya mengingat energi yang diberikan dalam proses pembelajaran memuat kopetensi yang berbeda-beda pada setiap bidangnya.

Kata ujian nasional atau disingkat UN adalah sistem evaluasi standar pendidikan dasar dan menengah secara nasional dan persamaan mutu tingkat pendidikan daerah yang dilakukan oleh pusat penilaian pendidikan (Dedy, 2017). Lebih lanjut, (Arifin, 2011) mengatakan bahwa evaluasi dilakukan oleh lembaga yang mandiri secara berskala, menyeruh, transparan dan sistematik untuk mendapatkan hasil yang memuaskan. Hal ini sejalan dengan penelitian yang di lakukan oleh Nurul Hidayah, bahwa ujian yang dimaksudkan untuk mengukur standar kelulusan dengan pencapaian target nilai yang telah di tetapkan, senyatanya bukan justru mampu mendongkrat dan memotivasi kelulusan namun lebih sebagai ajang berbagai kepentingan semata (Nurul, 2013). Oleh karena itu kajian sosiologi Pendidikan profentik menjelaskan bahwa suatu sekolah harus memiliki Output yang jelas yaitu, pertama kelulusan siswa dalam proses Pendidikan, kedua komponen sekolah sebagai sistem dalam pelaksanaan pendidikan disekolah Syarifuddin, 2013)

Selain itu, Faktor-faktor yang mempengaruhi hasil ujian nasional meliputi faktor internal yakni, pertama berkaitan dengan kondisi jasmani dan rohani siswa yang meliputi aspek fisiologis dan aspek psikologis, kedua faktor eksternal berkaitan dengan kondisi lingkungan disekitar siswa yang meliputi lingkungan sosial dan lingkungan non social (Silverius, 2010) 
Fenomena ujian nasional di kota Baubau dalam prakteknya menimbulkan beberapa ketimpangan, proses Pendidikan yang diharapkan sebagai muara ilmu pengetahuan seolah terpatahkan dengan berbagai aktifitas seremonial dalam proses ujian nasional. Untuk itu, studi ini membahas "sebab yang mendasari terjadinya ragam wacana dalam membentuk persepsi social sebagai standar ujian nasional".

\section{Metode}

Penelitian dilakukan dengan model deskriptif kualitatif, dalam pengumpulan data menggunakan tehnik observasi, dokumentasi, dan wawancara mendalam. Proses pengambilan sampel ditentukan melalui pusposivesampel melalui responden terpilih, terhadap evaluasi pelaksanaan ujian nasional dimana berpotensi melakukan pembodohan public dan kecurangan terencana (Moleong, 2007)

Selain itu, sampel dibantu melalui metode snowballsampling untuk memungkinkan memperoleh lebih banyak fakta-fakta dilapangan (Bungin, 2003) Lokasi penelitian ini berada di wilayah kota Baubau yang difokuskan pada sekolah tingkat SMU-sederajat

\section{Hasil}

Ujian nasional menjadi masalah baru dalam dunia pendidikan (Idi, 2014) Adanya standar mutu ditingkat pendidikan baik pusat maupun daerah berbeda, sejauh ini masalah UN menjadi momok tersendiri yang harus dihadapi oleh peserta didik bukan pada masalah standar atau kopetensi pembelajaran akan tetapi masalah menyikapi UN dalam rumpun keilmuan. Dalam hal ini kopetensi ilmu berbeda setiap elemennya begitupun soal bakat dan minat apalagi melibatkan standar nasional dengan penilaian mutu dan ini adalah hal yang berbeda. Kopetensi keilmuan seakan menjadi penilaian utama untuk menentukan lulus atau tidaknya peserta didik (Nawawi \& Hadari, 2006). Padahal program pendidikan didasarkan kepada tujuan umum pengajaran yang diturunkan dari tiga sumber: masyarakat, siswa, dan bidang studi. Mencakup konsep luas seperti membentuk manusia, menjadikan manusia pembangunan, manusia berkepribadian, manusia bertanggung jawab, dan sebagainya. Tujuan umum ini menyangkut pertimbangan filsafat dan etika yang diturunkan dari harapan masyarakat seperti apa yang tercantum dalam falsafah bangsa, tujuan pendidikan nasional, sifat lembaga pendidikan, nilai-nilai keagamaan, ideologi dan sebagainya (Nata, 2014).

Faktor-faktor yang mempengaruhi hasil ujian nasional meliputi :

\section{a. Aspek Internal}

Kondisi internal yang ada dalam diri peserta didik membawa pengaruh besar terhadap kesiapan menghadapi Ujian nasional. Karena mengakibatkan peserta didik terbebani dangan standar kelulusan yang telah ditetapkan oleh pemerintah. Kendatipun demikian, terdapat dua faktor internal yang mempengaruhi kesiapan menghadapi Ujian Nasional peserta didik yaitu faktor psikologi dan faktor jasmaniah: Faktor psikologi yang terbentuk dalam diri membawa pengaruh besar pada kecemasan yang berdampak pada kesiapan menghadapi UN.

Untuk itu, beban moral yang diakibatkan oleh rasa cemas yang berlebihan akan membuat perta didik merasa tertekan, seperti; 1) Takut mengalami 
kegagalan, 2) Mendapatkan nilai yang jelek, 3) Takut tidak bisa menjawab soal ujian. Sehingga kondisi seperti ini jelas peluang untuk bisa berhasil lulus ujian nasional menjadi sangatlah kecil. Sedangkan faktor jasmaniah yang di alami sepertl didik saat menghadapi ujian nasional seperti kesehatan dan cacat tubuh. Dengan keadaan siswa yang tidak fit, sakit atau bahkan stres, jelas akan mempengaruhi konsentrasi belajar siswa saat mengerjakan soal ujian sehingga siswa yang berada pada kondisi seperti inipun bukanlah mustahil pada akhinya gagal lulus ujian nasional.

b. Aspek Eksternal

Ujian nasional pada dasarnya membawa pengaruh pada lingkungan keluarga dan sekolah. Peran dalam menyiapkan diri untuk menghadapi UN membawa pada aspek beban moral yang berdampak pada kemampuan menerima informasi mengenai perkembangan pelaksanaan UN yang semakin hari semakin meningkat syarat angka kelulusannya. Beban yang terbentuk pada ruang sosial membawa pengaruh buruk pada perkembangan psikologis peserta didik dimana di tuntut untuk belajar lebih giat agar tidak membuat malu keluarga dan sekolah apabila peserta didik dinyatakan tidak lulus UN. Selain itu, gambaran aktifitas belajar peserta didik dikhususkan pada matapelajaran yang masuk ke daftar Ujian Nasional saja, sementara bakat dan minat peserta didik tidak menjadi bahan pertimbangan untuk modal pengetahuan yang akan menjadi standar penilaian. Untuk itu, materi penguasaan peserta didik dikhususkan mempelajari mata pelajaran tertentu saja, misalnya, IPA, IPS, Bahasa ( Indonesia dan Inggris) dan Matimatika.

Standar kelulusan yang ditentukan oleh pemerintah pada pelaksanaan ujian nasional membuat sejumlah peserta didik mengalami beban mental atau stress dalam mengejer materi yang akan diujiankan, padahal kemampuan peserta didik meliputi berbagai aspek tidak saja pada kemampuan umum yang akan diujiankan melaikan memiliki sejumlah pengetahuan dari berbagai displin ilmu dan kopetensi yang berbeda-beda. Untuk itu, pelaksanaan ujian nasional seharusnya bukan menjadi alasan penentu keberhasilan suatu pendidikan nasional karena standar pendidikan bertujuan untuk mencerdasakan kehidupan masyarakat secara berkesinambungan bukan untuk dinilai pada keberhasilan angka yang tertinggi. Gugusan Ujian nasional dewasa ini dijadikan sebagai acuan keberhasilan pendidikan di suatu daerah, oleh karena itu pihak sekolah negeri maupun swasta memberikan ultimatum kepada perangkat pendidikan untuk mengejok nilai peserta didik pada angka tertinggi diujian sekolah, dengan pertimbangan agar sekolahnya tidak mendapat sorotan apabila ditemukan peserta didik yang tidak lulus ujian nasional, gambaran ini menjadi fakta dalam lingkungan pendidikan di kota Baubau.

Analisis yang lain juga mengungkapkan bahwa tujuan pendidikan dasarnya setiap sekolah mendidik anak agar menjadi anggota masyarakat yang berguna. Namun, pendidikan disekolah sering kurang relevan dengan kehidupan masyarakat. Kurikulum kebanyakan berpusat pada bidang studi yang tersusun secara logis dan sistematis dan tidak nyata hubungannya dengan kehidupan sehari-hari peserta didik. Apa yang dipelajari peserta didik tampaknya hanya memenuhi kepentingan sekolah untuk ujian, bukan untuk membantu totalitas peserta didik agar hidup lebih efektif dalam masyarakat (Setiadi \& Kolip, 2011). 
Dari sini tampak bahwa perbedaan dimensi pendidikan nasional digagas melalui perkembangan ide agar tercipta kondisi yang memuat mutu pendidikan agar berkualitas dalam kehidupan peserta didik di masyarakat bukan dilihat dari keberhasilan ujian nasional dengan standar nilai maksimum yang ditetapkan oleh pemerintah sebagai keberhasilan proses pendidikan melalui tes ujian nasional semata. Apabila ini terjadi maka pendidikan dinilai sebagai kegiatan seremonial yang diukur dengan angka dan dilakukan setiap tahunnnya sebagai standar pencapaian mutu pendidikan di Indonesia.

Gambaran ini, menunjukkan ketidak dewasaan kita memandang mutu pendidikan hanya sebatas tes dan angka, pencapaian pendidikan dewasa ini harus dilihat kedalam beberapa aspek yang mempengaruhinya salah satunya terkait pada model pembelajaran yang diterapkan kedalam proses pembelajaran di sekolah. Oleh karena itu, sistem UN yang manipulatif pasti tidak memihak pada sekolah manapun karena tidak realistis. Bahkan, disadari atau tidak kelemahan pelaksanaan UN telah memberi dorongan terhadap tumbuhnya tindakan a moral dalam dunia pendidikan, termaksud tindakan terpaksa dan tak berdaya yang dilakukan pendidik atau guru dimana sebahagian mereka telah membantu menjawab item-item pernyataan pada soal. Pendidik atau guru yang sibuk sedangkan peserta didik yang santai. Bahkan indikasi ini merupakan proses pembodohan yang membuat peserta didik menjadi malas dan tak mandiri. Padahal, kualitas pendidikan nasional bukan selalu diukur dengan angka-angka tetapi dikedepankan dengan pentingnya kualitas kepribadian, moral, budi-pekerti, dan ahlak prilaku seperti diharapkan dalam konsep tujuan pendidikan nasional yakni yang menciptakan manusia Indonesia yang beriptek dan berimtak dan juga sebagai konsep cita-cita luhur pembangunan pendidikan nasional.

UN diharapkan dapat mendorong berbagai elemen untuk menjunjung tinggi dan mewujudkan cita-cita luhur pendidikan nasional tersebut. Evaluasi terhadap pelaksanan UN yang cenderung berpotensi melakukan "pembodohan publik" dan melakukan kecurangan terencana padahal sangat berbahaya bagi generasi masa depan bangsa, hendaknya segera ditinggalkan. Peserta didik akan jadi cerdas, berkepribadian, mandiri, trampil, bermoral, dan berahlak hanya jika iklim pendidikan memungkinkan peserta didik memperoleh pengetahuan yang mengedepankan kejujuran, displin, kerja keras, toleransi, dan transparansi dalam berbagai pergaulan di masyarakat. Antara pengetahuan (umum dan agama) harus berhubungan dengan prilaku peserta didik yang diharapkan. Sehingga bentuk pendidikan kita tidak menjadi wacana belaka.

\section{Pembahasan}

Gagasan ujian nasional yang dilaksanakan dewasa ini membawa ketimpangan social bagi peserta didik maupun pihak sekolah (Syah, 2013). Dimana peran sekolah sebagai pendidik seolah dikesampingkan dan hanya mengejar target kelulusan yang tinggi untuk memenuhi standar kelulusan yang ditetapkan oleh pemerintah dan diukur sebagai qoata semata. Artinya bahwa, standar ujian nasional ini pada prinsipnya hanya dijadikan sebagai standar atau prasyarat akan keberhasilan pendidikan disuatu daerah yang diukur secara respentatif saja tanpa menghiraukan cara yang ditempuh oleh praktisi pendidikan dalam hal ini sekolah dan prangkat pembelajarannya. 
Kondisi ini, menjadi tumpang-tindih antara konsep pendidikan dan pelaksanaan ujian nasional yang sejatinya membawa pada kerumitan memahami konsep pendidikan itu sendiri, produk pendidikan adalah memanusiakan manusia dalam berbagai aspek kehidupan social. Muara pendidikan dewasa ini tidak berperan sama sekali dalam aspek memanusiakan manusia secara karekter sehingga dominasi pendidikan hanya dilihat seberapa tinggi angka kelulusan yang diperoleh sekolah dan pemerintah secara kuantitatif tanpa menghiraukan perkembangan dan arah pendidikan peserta didik dalam membentuk kemampuannya. Maksudnya adalah pelaksanaan pendidikan tidak memberikan gambaran konkret akan masa depan yang akan digapai setelah tamat SMUsederajat dan bagaimana kebutuhan masyarakat dan potensi localistic di suatu daerah.

Peran pendidikan saat ini hanya sebatas rutinitas akademik yang dijalani sebagai porsi keharusan dalam aktifitas pendidikan sehari-hari, sekolah sebagai tempat menuntut ilmu dijadikan tameng untuk mengelola perangkat-perangkat pembelajaran yang ujungnya hanya untuk mengejar angka kelulusan yang tinggi agar nama baik sekolah tidak tercoreng. Kondisi ini menjadi gambaran bahwa pelaksanaan ujian nasional memang membawa berbagai ketimpangan dalam dunia pendidikan kita. Dimensi pendidikan tidak memberi solusi akan potensi peserta didik dan potensi daerah sebagai basis dari perkembangan pendidikan kita dan hubungannya dengan aspek perkembangan peserta didik itu sendiri.

Berdasarkan uraian tersebut di atas, dapat diketahui bahwa gambaran pelaksanaan ujian nasional dikota Baubau membawa berbagai ketimpangan akademik dan social sehingga menjadi aktifitas seremonial yang dilakukan oleh sekolah sebagai rutinitas tahunan dan mengakibatkan gejolak social yang tidak menentu dalam pembentukan karakter bangsa. Kondisi ini, menjadi sangat timpang dalam menentukan muatan pembelajaran yang orientasinya hanya pada rumpun ilmu yang di ujiankan tanpa melihat berbagai potensi akademik dalam diri peserta didik.

\section{Kesimpulan}

Pelaksanaan ujian nasional di kota Baubau menjadi berbagai sasaran dalam bentuk: Pengelompokkan rumpun ilmu, hanya terjebak tes dan angka-angka, membentuk tindakan a-moral, pembodohan publik, kehancuran generasi muda dan hanya menjadi wacana belaka di dunia social.

\section{Daftar Pustaka}

Arifin, Z. (2011). Evaluasi Pembelajaran. Remaja Rosdakarya.

Bungin, B. (2003). Analisis Data Penelitian Kualitatif, Pemahaman Filosofi dan Metodologi kearah Pembangunan Model Aplikas. Grafindo Persada.

Dedy, A. Z. (2017). Implementasi Manajemen Ujian Nasional Sekolaj Menengah Atas di Kota Mataram. Universitas Negeri Yogyakarta.

Idi, A. (2014). Sosiologi Pendidikan (Individu, Masyarakat, Pendidikan). Rajawali Press.

Irianto, A. (2011). Pendidikan sebagai Investasi dalam Pembangunan Suatu Bangsa. Kencana. 
Moleong, J. L. (2007). Metodologi Penelitian Kualitatif. Remaja Rosdakarya.

Muntholi'ah. (2013). Ujian Nasional, Dulu, Kini dan Akan Datang. Jurnal Pendidikan Islam, 7(1).

Nasution, S. (2009). Sosiologi Pendidikan. Bumi Aksara Press.

Nata, A. (2014). Sosiologi Agama Islam. Raja Grafindo Persada.

Nawawi, H., \& Hadari, M. (2006). Instrumen Penelitian Bidang Sosial. Gadjah Mada University Press.

Nursyam. (2017). Evektivitas Pelaksanaan Ujian Nasional Sekolah Menegah Atas Negeri 17 oleh Dinas Pendidikan dan Pengajaran Kota Palu Provinsi SulTengah. Katalogis, 5(9), 11-21.

Nurul, H. (2013). Ujian Nasional dalam Perspektif Kebijakan Publik. Majelis pada Daerah Aceh. Jurnal Pencerahan, 7(1), 35-40.

Setiadi, E. ., \& Kolip, U. (2011). Pengantar Sosiologi, Pemahaman Fakta dan Gejala Permasalahan Sosial: Teori, Aplikasi, dan Pemecahan. Kencana Prenada Media Group.

Silverius, S. (2010). Kontroversi Ujian Nasional Sepanjang Masa. Ournal Pendidikan Dan Kebudayaan, 16(2).

Syah, M. (2013). Psikologi Pendidikan. Remaja Rosdakarya. 